\title{
PROGRESSO DA FERRUGEM E DA CERCOSPORIOSE DO CAFEEIRO CONSORCIADO COM GREVÍLEA, COM INGAZEIRO E A PLENO SOL EM LAVRAS - MG
}

\author{
Progress of rust and coffee plant cercosporiose mixed with grevílea, with ingazeiro \\ and in the full sunshine in Lavras - MG
}

\author{
Bruno Grandi Salgado ${ }^{1}$, Renato Luiz Grisi Macedo ${ }^{2}$, Vicente Luiz de Carvalho ${ }^{3}$, Mirian Salgado ${ }^{4}$, Nelson Venturin ${ }^{5}$
}

\begin{abstract}
RESUMO
Com o presente trabalho, objetivou-se avaliar a incidência da ferrugem e da cercosporiose do cafeeiro em diferentes sistemas de cultivo, agroflorestais e a pleno sol, através da curva de progresso dessas doenças. Utilizou-se o delineamento inteiramente casualizado, com três tratamentos e sete repetições. Os tratamentos foram compostos por cafeeiros consorciados com ingazeiro, cafeeiros consorciados com grevílea e cafeeiros cultivados convencionalmente a pleno sol. As avaliações foram realizadas mensalmente no período de abril de 2001 a março de 2003. Realizou-se o cálculo da área abaixo da curva de progresso da doença (AACPD), a qual foi submetida à análise de variância. Para a incidência da ferrugem do cafeeiro o consórcio cafeeiro $x$ ingazeiro mostrou-se com maiores índices da doença, sendo que os tratamentos consórcio cafeeiro x grevílea e cafeeiro a pleno sol não diferiram entre si e apresentaram menores incidências da doença. Diminuição na luz solar direta e maior umidade podem ter favorecido a ferrugem no sistema cafeeiro $\mathrm{x}$ ingazeiro. Para a incidência de cercosporiose, os cafeeiros a pleno sol obtiveram maiores valores de incidência da doença, seguidos por cafeeiros x grevílea, e menores taxas da doença foram observadas no consórcio cafeeiros x ingazeiro. A incidência de radiação solar direta pode ter favorecido a maior incidência de cercosporiose nos cafeeiros a pleno sol.
\end{abstract}

Termos para indexação: Doenças do cafeeiro, sistemas agroflorestais.

\begin{abstract}
The present work aimed to evaluate the incidence of rust and coffee plant cercosporiose in different systems of agroforest cultivation and in the full sunshine through the progress curve of those diseases. The completely randomized design with three treatments and seven replicates was utilized. The treatments were made up of coffee plants mixed with ingazeiro, coffee plants mixed with grevílea and coffee plants cultivated conventionally in the full sunshine. The evaluations were performed monthly during the period of April 2001 to March 2003. The calculation of the area bellow the disease progress curve (ABDPC), which was submitted to the variance analysis. For the incidence of the coffee plant rust, the coffee plant $\mathrm{x}$ ingazeiro mixing presented the highest indices of the disease, the treatments coffee plant $\mathrm{x}$ grevílea mixing and coffee plant in the full sunshine did no differ from each other and presented the smallest indices of the disease. Decrease in the direct solar light and higher humidity may have supported rust in the coffee plant $\mathrm{x}$ ingazeiro system. For the incidence of cercosporiose, the coffee plants in the full sunshine obtained higher values of incidence of the disease followed by coffee plants $\mathrm{x}$ grevílea and lowest rates of the disease were found in the coffee plant $\mathrm{x}$ ingazeiro mixings. The incidence of direct solar radiation may have supported the highest incidence of cercosporiose on the coffee plants in the full sunshine.
\end{abstract}

Index terms: Coffee plants diseases, agroforestry systems.

(Recebido em 27 de abril de 2004 e aprovado em 8 de novembro de 2005)

\section{INTRODUÇÃO}

O estudo epidemiológico das interações patógeno, hospedeiro e ambiente é fundamental para o manejo das doenças das plantas. Assim, o conhecimento dos fatores que influenciam o desenvolvimento das doenças é de suma importância para a obtenção de êxito no manejo.
No que diz respeito ao ambiente, a pluviosidade, a temperatura e a umidade do ar afetam tanto a incidência quanto a severidade da doença. As condições de manejo, como a utilização de árvores consorciadas aos cafeeiros podem afetar a intensidade das doenças devido à alteração do microclima em que a planta se insere e, conseqüentemente, no ambiente da cultura.

${ }^{1}$ Mestre - Departamento de Ciências Florestais/DCF - Universidade Federal de Lavras/UFLA - Cx. P. 3037 - $372000-000$ - Lavras, MG brunoflorestal@gmail.com

${ }^{2}$ Doutor, Professor Associado - Departamento de Ciências Florestais/DCF - Universidade Federal de Lavras/UFLA - Cx. P. 3037 - $37200-000$ Lavras, MG - regrisi@ufla.br

${ }^{3}$ Mestre, Pesquisador - Empresa de Pesquisa Agropecuária de Minas Gerais/EPAMIG - 37200-000 - Lavras, MG - vicentelc@epamig.br ${ }^{4}$ Mestre, Pesquisadora - Departamento de Fitopatologia/DFP - Universidade Federal de Lavras/UFLA - Cx. P. 3037 - $37200-000$ - Lavras, MG miriam@ufla.br

${ }^{5}$ Doutor, Professor Titular - Departamento de Ciências Florestais/DCF - Universidade Federal de Lavras/UFLA - Cx. P. 3037 - $37200-000$ - Lavras, MG venturim@ufla.br 
Dentre as principais doenças que afetam o cafeeiro, destacam-se a ferrugem (Hemileia vastatrix Berk \& Br.) e a cercosporiose (Cercospora coffeicola Berk \& Cooke), com prejuízos que variam de acordo com a intensidade da doença (incidência e severidade). Essas doenças promovem uma desfolha precoce nas plantas, principalmente pela produção de etileno nas folhas lesionadas, podendo diminuir consideravelmente a produção de café (ZAMBOLIM et al., 1997).

Em determinadas regiões do Brasil, onde ocorre déficit hídrico, os consórcios de cafeeiros com árvores podem atuar diminuindo a insolação e a perda de água, em locais suscetíveis à geada essa atuação é ainda mais significativa, evitando os danos causados pelas baixas temperaturas do ar (MACEDO, 2000).

Devido aos elevados custos de produção da cafeicultura e a um mercado cada dia mais competitivo, há a necessidade de evitar quaisquer formas de perda. Assim, para a correta adoção da arborização, torna-se necessário conhecer a dinâmica de ocorrência de doenças nesses sistemas de cultivo de cafeeiros sombreados. Poucos são os estudos que relacionam doenças e arborização do cafeeiro, justificando, assim, pesquisas para a geração de conhecimento nesta área.

O presente trabalho objetivou avaliar a incidência da doença e a obtenção das curvas de progresso da doença para a ferrugem e a cercosporiose dos cafeeiros (Coffea arabica), consorciados com Ingazeiro (Inga vera Willd) e grevílea (Grevilea robusta Cunn.) e cafeeiros cultivados a pleno sol no município de Lavras, Minas Gerais.

\section{MATERIAL E MÉTODOS}

A cidade de Lavras localiza-se no sul do Estado de Minas Gerais, a $900 \mathrm{~m}$ de altitude, latitude de $21^{\circ} 14^{\prime} \mathrm{S}$ e longitude de $45^{\circ} 00^{\prime} \mathrm{W}$. Apresenta clima do tipo CWa segundo a classificação de Koppen. A temperatura média anual é de $19,4^{\circ} \mathrm{C}$, com a média da máxima de $26,1^{\circ} \mathrm{C}$ e a média da mínima de $14,8^{\circ} \mathrm{C}$; a precipitação média anual é de1529,7 mm (BRASIL, 1992).

O cafeeiro estudado é da variedade Mundo Novo, plantado no espaçamento 4 x $1 \mathrm{~m}$ nos três sistemas e com mesma idade. Os cafeeiros foram recepados a cinco anos, encontrando-se em plena produtividade, sendo que nos sistemas agroflorestais ocorrem as seguintes distribuições espaciais:

1) Cafeeiro $x$ ingazeiro: Uma linha de cafeeiro arborizada e uma linha solteira, árvores distanciadas a 15 metros na linha de plantio e 8 metros na entrelinha. $\mathrm{O}$ ingazeiro foi plantado juntamente com os cafeeiros, estando hoje com a idade de 15 anos (Figura 1).
2) Cafeeiro $x$ grevílea: Uma linha de cafeeiro arborizada e duas linhas solteiras, árvores distanciadas a 10 metros na linha de plantio e 12 metros na entrelinha. A grevílea foi plantada com o cafeeiro já formado, estando hoje com a idade de 9 anos (Figura 2).

O experimento foi avaliado no delineamento experimental inteiramente casualizado, com sete repetições e composto por três tratamentos (cafeeiro a pleno sol, cafeeiro consorciado com ingazeiro e cafeeiro consorciado com grevílea).

Em cada sistema de cultivo (tratamentos) foram sorteadas, ao acaso, sete parcelas (compostas por vinte plantas de cafeeiro cada uma), nas quais foram realizadas as coletas de folhas para a contagem das doenças. Ao redor de cada parcela, composta de vinte plantas de cafeeiros, foi estabelecida uma bordadura, separando as repetições dentro de cada tratamento. Assim, a parcela possui um total de 66 plantas de cafeeiro (três linhas x 22 plantas), com uma área total de $63 \mathrm{~m}^{2}$.

Com o objetivo de monitorar a incidência da ferrugem e cercosporiose foram realizadas avaliações mensais nas parcelas, por dois anos, no período de abril de 2001 a março de 2003.

Avaliou-se a incidência da ferrugem e cercosporiose coletando-se 5 folhas por planta, num total de vinte plantas por parcela. As folhas foram coletadas ao acaso, no terço médio da planta, do $3^{\circ}$ e $4^{\circ}$ pares de folhas a partir do ápice do ramo, totalizando 100 folhas por parcela. Contou-se o número de folhas com presença de pústulas esporuladas, obtendo-se a porcentagem de incidência da ferrugem. A contagem foi realizada da mesma forma para a cercosporiose, contando-se o número de folhas com a lesão da doença.

Após a obtenção dos dados de incidência da doença, foram plotadas as curvas de progresso da doença. Calculou-se então a área abaixo da curva de progresso da doença (AACPD) por meio da equação proposta por Campbell \& Madden (1990):

$$
\text { AACPD }=\frac{\sum_{i=1}^{n-1} Y i+Y i+1}{2} \times(T i-1-T i)
$$

em que:

AACPD: Área abaixo da curva de progresso da doença; Yi = Proporção da doença na i-ésima repetição;

$\mathrm{Ti}$ = Tempo em dias na i-ésima observação;

$\mathrm{n}=$ Número total de observações. 


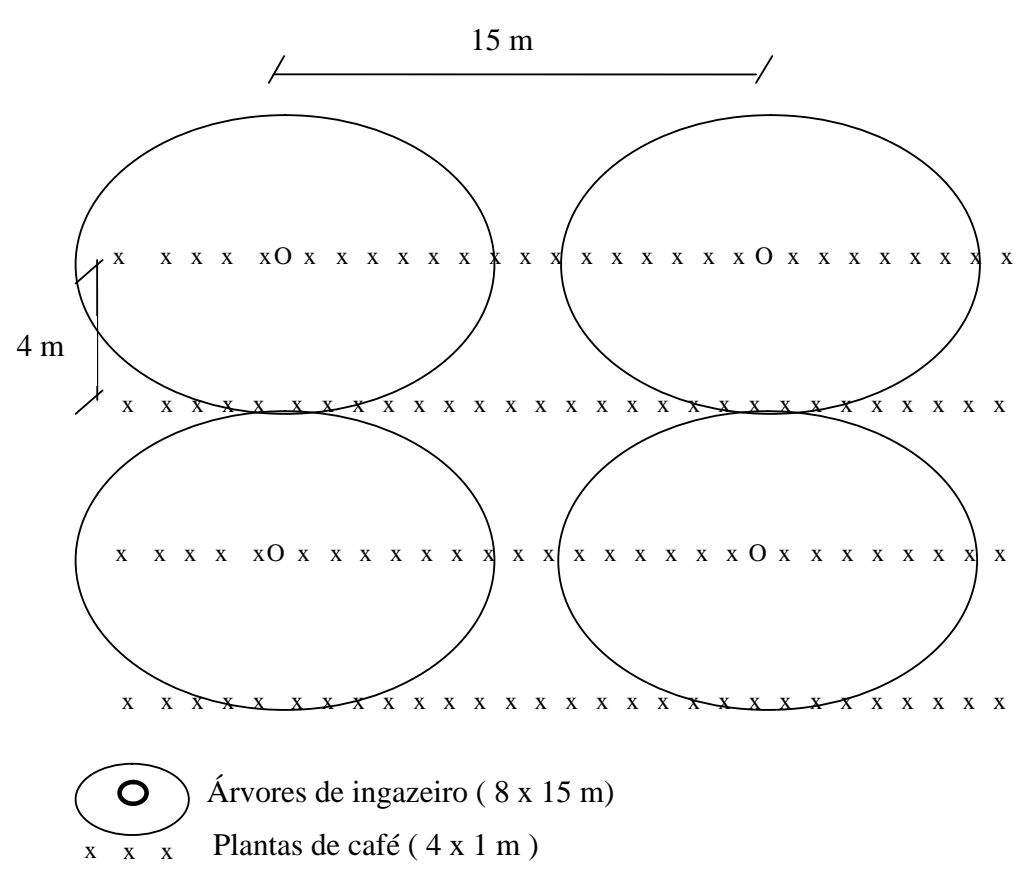

FIGURA 1 - Representação do cultivo de cafeeiros consorciados com ingazeiros.

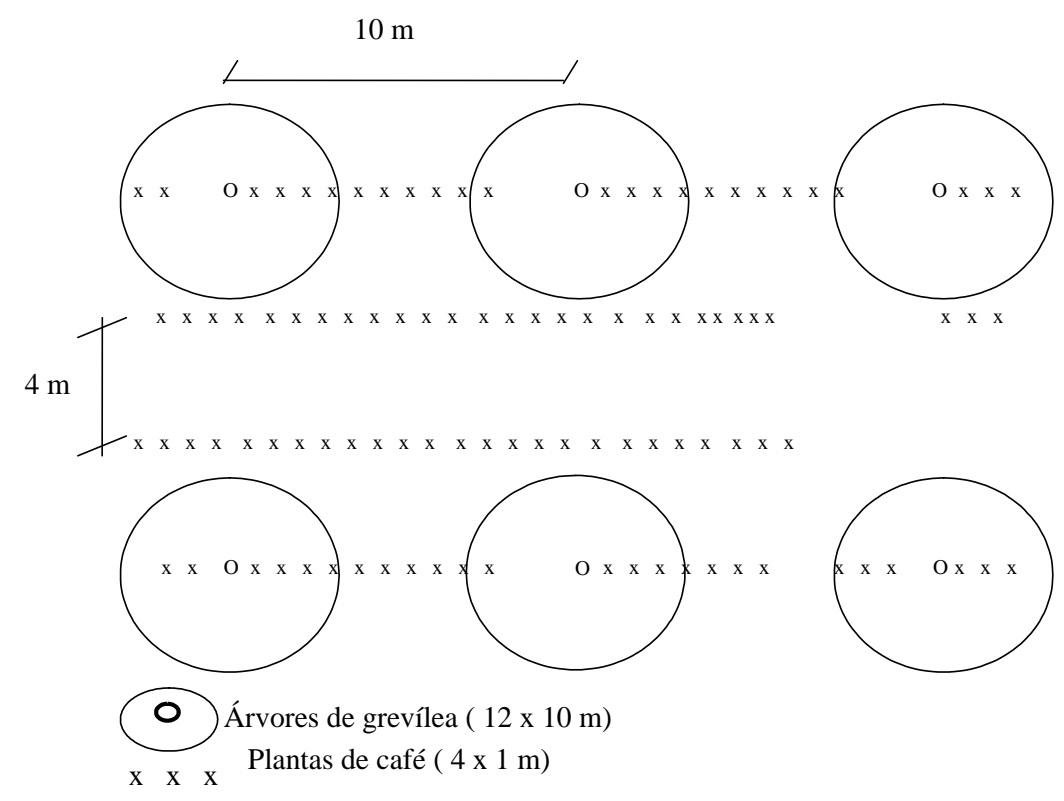

FIGURA 2 - Representação do cultivo de cafeeiros consorciados com grevílea. 


\section{RESULTADOS E DISCUSSÃO}

\section{A) Ferrugem do cafeeiro}

A curva de progresso da incidência da ferrugem nos cafeeiros entre os meses de abril de 2001 a março de 2003, nos três diferentes sistemas de cultivo (cafeeiro $x$ grevílea, cafeeiro x ingazeiro e cafeeiro a pleno sol), está representada na Figura 3. Os resultados da análise de variância demonstraram uma diferença significativa na incidência da ferrugem do cafeeiro $(\mathrm{P}<0,05)$ no sistema cafeeiro $\mathrm{x}$ ingazeiro, em relação ao cultivo a pleno sol e cafeeiro $\mathrm{x}$ grevílea (Tabela 1 ).

TABELA 1 - Resumo da análise de variância sobre a área abaixo da curva de progresso da incidência de ferrugem, em função de diferentes sistemas de consórcios com cafeeiros (cafeeiro x ingazeiro, cafeeiro x grevílea e cafeeiros a pleno sol).

\begin{tabular}{lccc}
\hline $\begin{array}{l}\text { Fontes de } \\
\text { variação }\end{array}$ & G.L. & Q.M. & F \\
\hline $\begin{array}{l}\text { Sistemas de } \\
\text { cultivo }\end{array}$ & 2 & 5408775,00 & $11,30^{* *}$ \\
$\begin{array}{l}\text { Resíduo } \\
\text { CV }=11,66\end{array}$ & 18 & 478264,28 & \\
\hline
\end{tabular}

** Significativo a 5\% de probabilidade.

A incidência de ferrugem nos cafeeiros cultivados a pleno sol e cafeeiro $\mathrm{x}$ grevílea não apresentaram diferença significativa (Tabela 2 ).

TABELA 2 - Valores médios da área abaixo da curva de progresso da incidência (AACPD) de ferrugem em cafeeiros, em função de diferentes sistemas de cultivo.

\begin{tabular}{ll}
\hline $\begin{array}{l}\text { Sistemas de cultivo } \\
\text { do cafeeiro }\end{array}$ & AACPD \\
\hline Cafeeiro a pleno sol & $5335,71 \mathrm{a}$ \\
Cafeeiro x Grevílea & $5522,14 \mathrm{a}$ \\
Cafeeiro x Ingazeiro & $6942,85 \mathrm{~b}$ \\
\hline
\end{tabular}

Médias seguidas da mesma letra não diferem entre si pelo teste de Scott-Knott $(\mathrm{P}<0,05)$.
Segundo Carvalho et al. (1999) e Matiello (1991), dentre as condições ambientais ideais ao desenvolvimento da doença estão o sombreamento e os espaçamentos mais fechados (levando esses a um auto-sombreamento), o que poderia estar favorecendo a ferrugem no sistema consorciado com ingazeiro, já que as árvores podem estar acentuando estas condições favoráveis ao fungo.

Uma maior área é sombreada pelos ingazeiros, devido a várias bifurcações e a ampla conformação de sua copa, que possui crescimento horizontal, chegando as mesmas a se encontrarem. Já a grevílea proporciona um sombreamento menos efetivo, devido seu fuste reto e uma copa com menor expansão lateral. Esta diferença de arquitetura das árvores pode favorecer diferenças de microclima existentes entre os sistemas.

Campbell \& Madden (1990) confirmam que a temperatura é a variável que mais influencia nos componentes biológicos do patossistema no desenvolvimento de uma epidemia. Além disso, os autores relacionam a umidade do solo e do ar, representada pelos vários estádios, formas e energia da água. $\mathrm{O}$ vento, atuando no transporte do inóculo. A radiação solar, energia primária para muitos processos biológicos e físicos, na ocorrência do ciclo de vida do patógeno. Assim, a correlação de variáveis dos ambientes físico e biológico dificultam a determinação exata de quais fatores e quando esses fatores influenciaram ou dificultaram a ação do patógeno.

Segundo Almeida (1986), o fungo da ferrugem necessita de água livre, temperatura na faixa de 21 a $23^{\circ} \mathrm{Ce}$ ausência de luz direta para germinação e penetração dos uredosporos pelos estômatos da folha. Espera-se, após a ocorrência de uma chuva ou orvalho, que no sistema cafeeiro $\mathrm{x}$ ingazeiro o período de molhamento foliar dure mais tempo, já que a copa das árvores dificulta a incidência de luz direta nos cafeeiros, favorecendo o desenvolvimento da doença.

Apesar de não estudadas as diferenças na incidência solar direta nos cafeeiros e a umidade relativa entre os sistemas estudados, estas podem ser responsáveis, em grande parte, pela maior incidência da ferrugem no sistema composto por ingazeiros.

Há uma interação entre a ação da ferrugem, ou de qualquer outra praga ou doença, que produz lesões, e a ação do frio, parecendo que o frio abrevia a queda de folhas, provavelmente pela maior produção de etileno, atribuída à morte do micélio de fungo e à aceleração do processo de morte do tecido foliar (CARNEIRO FILHO, 1998). Diante disso, os cafeeiros nos sistemas arborizados podem ser favorecidos por menor perda de folhas lesionadas, já que 


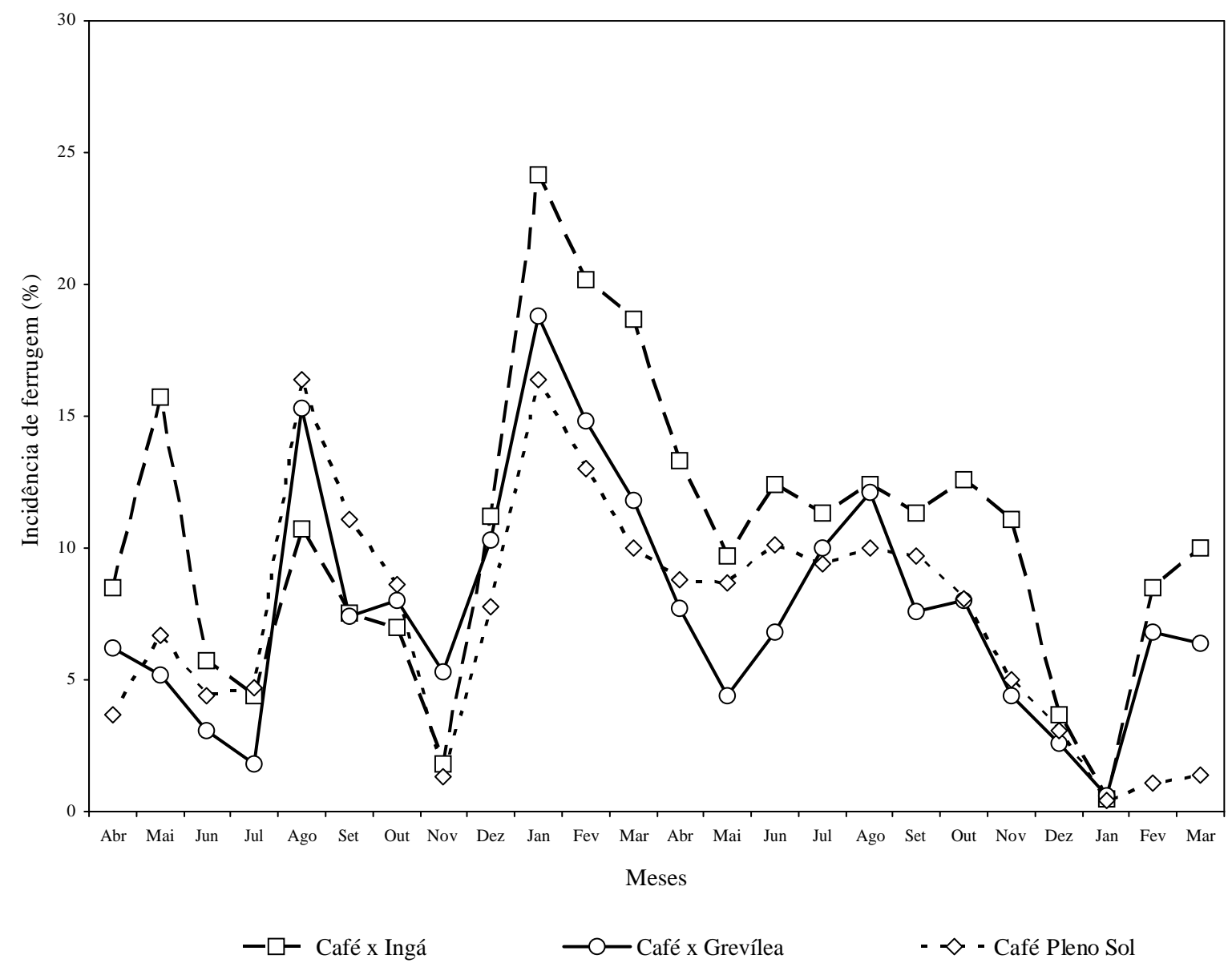

FIGURA 3 - Gráfico do progresso da incidência de ferrugem em cafeeiros consorciados com ingazeiro, cafeeiros com grevílea e cafeeiros a pleno sol, no período de abril de 2001 a março de 2003.

esses sistemas atuam alterando a temperatura do ar, impedindo a ocorrência de frio severo e sua atuação negativa quanto à queda prematura dessas folhas.

No ano de 2001 (Figura 3), a ferrugem apresentou uma mesma tendência para os três sistemas de cultivo estudados, ocorrendo um grande aumento de incidência de julho para agosto, onde nesse último mês observou-se a maior incidência da doença naquele ano.

Talamini (1999), acompanhando a ferrugem em cafeeiros adultos em Lavras, entre março de 1998 e fevereiro de 1999, também observou pontos de máxima nos meses de julho a outubro.

De novembro de 2001 a janeiro de 2002 observouse um aumento generalizado na incidência da ferrugem para os três sistemas, voltando a decrescer até o mês de maio.

A partir de maio de 2002 a incidência da doença volta a ter um aumento em seus índices, apresentando, nesse período, comportamento mais próximo ao considerado padrão para Minas Gerais, com aumento da doença nos meses de março a abril e maiores incidências por volta do mês de junho.

\section{B) Cercosporiose do cafeeiro}

A incidência da cercosporiose nos cafeeiros entre os meses de abril de 2001 e março de 2003, nos três diferentes sistemas de cultivo (cafeeiro $\mathrm{x}$ grevílea, cafeeiro $\mathrm{x}$ ingazeiro e cafeeiro a pleno sol), é apresentada na Figura 4. 
Os resultados da análise de variância demonstraram uma diferença significativa quanto ao progresso da incidência da cercosporiose do cafeeiro $(\mathrm{P}>0,05)$, para os três sistemas de cultivo de cafeeiros estudados (Tabela 4).

A incidência da cercosporiose foi mais elevada nos cafeeiros a pleno sol, decrescendo para cafeeiros $\mathrm{x}$ grevílea e cafeeiros x ingazeiro, conforme é apresentado na Tabela 5.

TABELA 4 - Resumo da análise de variância sobre a área abaixo da curva de progresso da incidência de cercosporiose, em função de diferentes sistemas de consórcios com cafeeiros (cafeeiro x ingazeiro, cafeeiro $\mathrm{x}$ grevílea e cafeeiros a pleno sol).

\begin{tabular}{cccc}
\hline $\begin{array}{c}\text { Fontes de } \\
\text { variação }\end{array}$ & G.L. & Q.M. & F \\
\hline $\begin{array}{c}\text { Sistemas de } \\
\text { cultivo }\end{array}$ & 2 & 9881671,7 & $334,15^{* *}$ \\
Resíduo & 18 & 29572,01 & \\
CV $=8,34$ & & & \\
\hline
\end{tabular}

TABELA 5 - Valores médios de área abaixo da curva de progresso da doença (AACPD) cercosporiose em cafeeiro, em função de diferentes sistemas de cultivo.

\begin{tabular}{ll}
\hline Sistemas de cultivo do cafeeiro & AACPD \\
\hline Cafeeiro x Ingazeiro & $800,42 \mathrm{a}$ \\
Cafeeiro x Grevílea & $2223,0 \mathrm{~b}$ \\
Cafeeiro a pleno sol & $3160,14 \mathrm{c}$ \\
\hline
\end{tabular}

De acordo com vários autores (CARVALHO \& CHALFOUN, 1998; ECHANDI, 1959; MANSK, 1990; TALAMINI, 1999), as principais causas da acentuada intensidade da cercosporiose são o déficit hídrico associado à deficiência ou desequilíbrio nutricional. Provavelmente o cafeeiro a pleno sol estaria mais suscetível à cercosporiose devido à menor umidade do solo, decorrente da maior exposição direta ao sol neste sistema. No sistema sombreado, onde o solo pode permanecer úmido por mais tempo, também o cafeeiro absorveria água e nutrientes por um maior período de tempo, amenizando as condições de stress hídrico e nutricional favoráveis ao fungo da cercosporiose.

Santos (2002), em experimento relacionando níveis de lâmina de irrigação e incidência de cercosporiose, observou que os maiores índices da doença foram observados nas parcelas não irrigadas, indicando uma influência positiva na disponibilidade de água para a planta na redução da incidência da doença. Frente a essas considerações, espera-se que os sistemas arborizados disponibilizem água por um período de tempo mais longo aos cafeeiros, primeiro pela menor radiação incidente no solo e menor evaporação e, segundo, pela capacidade natural que as árvores têm de interceptação da água da chuva e infiltração da mesma, diminuindo o escoamento superficial e aumentando a retenção de água no solo.

Segundo Carvalho (1994), a espécie arbórea componente do sistema em que foi observada a menor incidência da cercosporiose, o ingá, apresenta associação simbiótica com Rhizobium, formando nódulos globosos e com atividade nitrogenase, sendo assim, uma fixadora de nitrogênio no solo. Vários autores (CARVALHO \& CHALFOUN, 1998; POZZA, 1999; SANTOS, 2002) consideram que as plantas de café deficientes em nitrogênio são mais suscetíveis à cercosporiose, assim, a decomposição da matéria orgânica composta por folhas, galhos e frutos das árvores pode estar favorecendo a menor incidência da doença pelo aumento da disponibilidade deste nutriente ao cafeeiro.

Cafeeiros cultivados a pleno sol encontram um ambiente físico mais propício ao desenvolvimento da doença do que aqueles cultivados à sombra. A cercosporiose necessita de um excesso de insolação e temperaturas mais elevadas para a germinação dos esporos do fungo, ocorrendo aos $30^{\circ} \mathrm{C}$, e também para seu crescimento, aos $24{ }^{\circ} \mathrm{C}$ (ECHANDI, 1959; ZAMBOLIM et al., 1997).

No sistema cafeeiro $\mathrm{x}$ ingazeiro a incidência manteve-se baixa e estável ao longo dos dois anos de avaliação, com as maiores incidências alcançando apenas 2,57\% em março de 2003. Nos cafeeiros consorciados com grevílea a incidência não ultrapassou os $10 \%$, sendo que em maior parte das avaliações o índice foi inferior a $4 \%$. Os cafeeiros a pleno sol apresentaram os maiores valores de incidência da cercosporiose durante quase todo o período avaliado. Nos anos de 2002 e 2003 o sistema a pleno sol obteve incidências bem superiores $(8,7$ e $11 \%$, respectivamente), se comparadas aos sistemas de cultivo sombreados. 


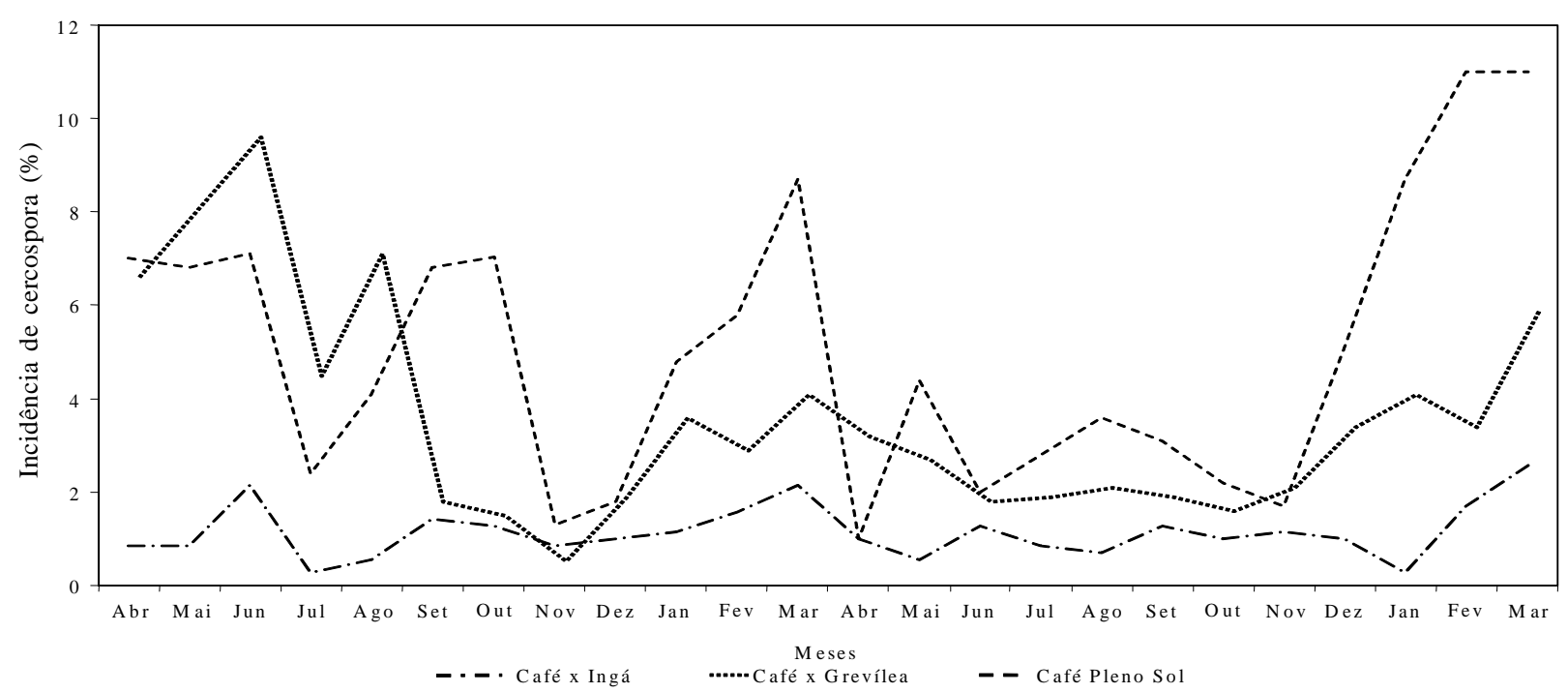

FIGURA 4 - Gráfico do progresso da incidência da cercosporiose em cafeeiros consorciados com ingazeiro, cafeeiros com grevílea e cafeeiros a pleno sol, no período de abril de 2001 a março de 2003.

\section{CONCLUSÕES}

Em cafeeiros consorciados com ingazeiro (espaçamento de $8 \times 15 \mathrm{~m}$ ), a incidência de ferrugem foi superior à de cafeeiros consorciados com grevílea (espaçamento de $12 \times 10 \mathrm{~m}$ ) e de cafeeiros cultivados a pleno sol.

A maior incidência da ferrugem foi observada em janeiro de 2002, para os três sistemas de cultivo avaliados.

A incidência de cercosporiose foi diretamente afetada pela arborização da lavoura cafeeira. Maiores incidências ocorreram nos cafeeiros a pleno sol, seguidas dos consorciados com grevílea e, por último, dos cafeeiros consorciados com ingazeiro.

As maiores incidências de cercosporiose ocorreram, durante o período avaliado, em 2001, no mês de junho, e em 2002 e 2003, nos meses de fevereiro e março.

\section{REFERÊNCIAS BIBLIOGRÁFICAS}

ALMEIDA, S. R. Doenças do cafeeiro. In: RENA, A. B.; MALAVOLTA, E.; ROCHA, M.; YAMADA, T. Cultura do cafeeiro: fatores que afetam a produtividade. Piracicaba: Associação Brasileira para Pesquisa da Potassa e do Fosfato, 1986. p. 391-399.

RASIL. Ministério da Agricultura e Reforma Agrária. Normais climatológicas de 1961-1990. Brasília, DF, 1992. $84 \mathrm{p}$.
CAMPBELL, C. L.; MADDEN, L. V. Introduction to plant disease epidemiology. New York: J. Wiley, 1990. $532 \mathrm{p}$.

CARNEIRO FILHO, F.; MOURA, A. C.; ISHIZAKA, A. M. Interação entre a infecção pela ferrugem e efeito do frio na desfolha de cafeeiros, após geadas fracas. In: CONGRESSO BRASILEIRO DE PESQUISAS CAFEEIRAS, 15., 1998, Maringá. Resumos... Maringá: IBC, 1998. p. 89-90.

CARVALHO, P. E. R. Espécies florestais brasileiras: recomendações silviculturais, potencialidades e uso da madeira. Colombo: Embrapa/CNPF; Brasília, DF: Embrapa/ SPI, 1994. p. 288-291.

CARVAlHO, V. L. de; CHALFOUN, S. M. Manejo integrado das principais doenças do cafeeiro. Informe Agropecuário, Belo Horizonte, v. 19, n. 193, p. 27-35, 1998.

CARVALHO, V. L. de; SALGADO, M.; CHALFOUN, S. M.; SALGADO, B. G. Comportamento das doenças do cafeeiro em plantios adensados. In: CONGRESSO BRASILEIRO DE FITOPATOLOGIA, 32., 1999, Curitiba. Resumos Expandidos... Curitiba: SBF, 1999. 
ECHANDI, E. La chasparria de los cafetos causada por el hongo Cercospora coffeicola Berk \& Cooke. Turrialba San Jose, v. 9, n. 2, p. 54-67, abr./jun. 1959.

MACEDO, R. L. G. Princípios básicos para o manejo sustentável de sistemas agroflorestais. Lavras: UFLA/ FAEPE, 2000. 157 p.

MANSK, Z. Doenças do cafeeiro. In: CONGRESSO BRASILEIRO DE PESQUISAS CAFEEIRAS, 16., 1990, Espírito Santo do Pinhal. Resumos... Rio de Janeiro: LBC, 1990. p. 61-77.

MATIELLO, J. B. O café: do cultivo ao consumo. São Paulo: O Globo, 1991. 320 p.

POZZA, A. A. A. Influência da nutrição nitrogenada e potássica na intensidade da mancha de olho pardo (Cercospora coffeicola) em mudas de cafeeiro. 1999. 70 p.
Dissertação (Mestrado em Fitopatologia) - Universidade Federal de Lavras, Lavras, 1999.

SANTOS, F. da S. Progresso da ferrugem e da cercosporiose em cafeeiro (Coffea arabica L.) irrigado. 2002. 71 p. Dissertação (Mestrado em Fitopatologia) Universidade Federal de Lavras, Lavras, 2002.

TALAMINI, V. Progresso da ferrugem e da cercosporiose do cafeeiro (Coffea arabica L.) irrigado e fertirrigado por gotejamento. 1999. 89 p. Dissertação (Mestrado em Fitopatologia) - Universidade Federal de Lavras, Lavras, 1999.

ZAMBOLIM, L.; VALE, F. X. R. do; PEREIRA, A. A.; CHAVES, G. M. Café (Coffea arabica L.) controle de doenças. In: VALE, F. X. R. do; ZAMBOLIM, L. Controle de doenças de plantas: grandes culturas. Viçosa: UFV; Brasília, DF: Ministério da Agricultura e Abastecimento, 1997. v. 2, p. 83-179. 